\title{
Equilibria and entry in two interdependent spatial markets
}

\author{
Nicolas Schmitt* \\ Simon Fraser University, Burnaby, B.C., V5A IS6, Canada \\ Received November 1988, final version received April 1991
}

This paper investigates the market equilibrium and entry location in two interdependent spatial markets. It is first shown that for some international trade problems, an explicit two-market spatial model with a representative firm brings more general results than those obtained with existing approaches. Then, modifying the game, entry location is analyzed and import replacement strategy is shown to be a strong feature of the model. This possible strategy of entry provides an incentive to incumbent firms to establish multi-market production.

\section{Introduction}

The purpose of this paper is to analyze the market equilibrium and the choice of entry location in interdependent spatial markets separated by arbitrary barriers to trade (tariff, transport cost) by using an explicit multispatial market model.

To understand the importance of the multi-market specification, consider two examples in international trade theory that the analysis wants to capture. Suppose first one wants to investigate the effects of bilateral trade liberalization on the market structure (price, number of firms, etc.) in a differentiated product industry in which firms export in each other's market. Since trade liberalization usually occurs between countries that already trade, a crucial aspect of this problem is to be able to predict how the market equilibrium is affected by small changes in reciprocal tariff. If each market is represented by a spatial representation, an explicit two-market specification becomes a useful tool to characterize the equilibrium for arbitrary tariff rate. It requires, however, knowledge of the product arrangement in the two markets, as well as a precise specification of the role of tariff on the firm's choice.

The second example is closely related and pertains to entry. The literature

Correspondence to: Prof. N. Schmitt, Department of Economics, Simon Fraser University, Burnaby, B.C., V5A 1S6, Canada.

${ }^{*}$ I wish to thank J.-F. Thisse and an anonymous referee for helpful comments. Financial support from the Social Sciences and Humanities Research Council of Canada is gratefully acknowledged. 
on multinationals and foreign investments suggests that barriers to trade affect the firm's choice of entry [see Caves (1982), Horstmann and Markusen (1987)]. Since spatial market representation offers a natural framework to analyze entry, multi-market models can also shed some light on this issue.

The effects of trade liberalization are analyzed in the intra-industry trade literature, but explicit multi-market specification is surprisingly scarce since most papers analyze limiting cases of market interdependency. In particular, the market structure effects of freer trade are not usually identified by varying tariff, but by varying the consumers' density (or units of labor) in one market [Krugman (1979, 1980); Lancaster (1980)]. In effect, in the presence of two identical markets, changing tariff from its prohibitive level to zero is analytically cquivalent to doubling the consumers' density on one market. If this simple methodology is appropriate to investigate several problems, it is clearly inappropriate to describe the market equilibrium between these two limits. Lancaster (1984) uses an explicit two-market model to show how tariff changes affect the market equilibrium. However, results are derived with numerical examples so that it is not known how they can be generalized to arbitrary tariff rate and how they compared with models that vary consumers' density.

To our knowledge, there is no precise analysis of entry behavior in multispatial markets. The intra-industry trade literature does not analyze this issue since most papers look at a one-stage game in prices [Lancaster (1980); Helpman (1981)]. This does not mean that there is no interest in multinationals, but that other motives are investigated [see Helpman and Krugman (1985)]. Lyons (1984), for instance, uses an explicit two-market model to show that multinational firms can best capture rents when they are multi-product firms and when products have fixed characteristics.

In this paper, aspects of both issues are investigated by considering the case of two geographically separated but identical and interdependent spatial markets. The structure of the spatial model remains simple so that the equilibrium for arbitrary inter-market shipping costs can be fully characterized. Restricting attention to symmetric and interleaved equilibria (i.e. where each domestic firm competes directly with two importers), two different games are considered.

In the first one, firms make entry decisions simultaneously as they select prices taking as given those of their rivals. Since locations are symmetric and interleaved, the equilibrium distance between firms is derived from a zeroprofit condition. Following Salop (1979), who analyzes this game in the single-market context, we call the solution the symmetric equilibrium with zero-profit. This game serves its purpose in showing that the results are more general than in most existing intra-industry trade models, since it not only provides equilibrium solutions for any inter-market shipping costs, but it also replicates the main accepted results. 
The second game is more sophisticated since the market equilibrium results from a two-stage game. In the first stage, a single entrant selects its location knowing and taking as given the symmetric and interleaved locations of existing firms, and in the second stage, all firms select prices in a simultaneous move. This game serves two purposes: first, the entry decision can be analyzed in detail and, in particular, the effects of changes in the parameters of the model on entry location. Not surprisingly, it depends strongly on the shipping cost. It is shown, for instance, that entrants have a strong incentive to select the same location as importers, and thus to replace imports. The second purpose is to show that this entry behavior may affect the existing firm's organization of production, and induce it to establish multi-market production. To do so, the free-entry equilibrium is derived, that is, the equilibrium in which the potential firm expects no positive profit in the post-entry equilibrium. It is then shown that, depending on the additional cost of producing abroad, the equilibrium profit of existing firms can be larger by forming a multinational than by concentrating production in one market and trading, because the former strategy eliminates the entrant's incentive to replace imports. An equivalent game in a one-market environment was first analyzed by Eaton and Wooders (1985). Since the free-entry equilibrium exhibits pure profits, we call it the symmetric equilibrium with pure profits. Both games are set in the same multi-firm environment in order to facilitate comparison with the existing literature on product differentiation.

This paper fills a gap in the literature both because it derives analytically the equilibrium for any inter-market shipping cost (or tariff) and because it investigates entry behavior in a multi-spatial market model. It is organized as follows: in section 2 the model is laid out and the interleaved arrangement is justified. In section 3, the zero-profit equilibrium is derived and compared with existing results. Section 4 analyzes the entrant's behavior and the freeentry equilibrium, while section 5 summarizes the main results.

\section{The model}

The model can be interpreted either as a model of spatial competition or as a model of competition in some characteristics space. For simplicity, the former interpretation is considered. There are two identical markets and, in each of them, the continuum of possible locations is the real line. The real line is used in order to avoid the well-known problems associated with market boundaries. Each firm produces a single good at one location in one market only, but each good can be sold in both markets. If a good is consumed in the same market as it is produced (domestic product), the mill price of product $i$ is $p_{i}$. If this product is consumed in another market (foreign product), it is shipped at a specific cost $t$ (assumed to be the same for all products whatever the direction of trade) to this market and sold by 
the firm at the same relative location as in the market where it is produced. The mill price of product $i$ in its foreign market is $\left(q_{i}+t\right)$, where $q_{i}$ is the net foreign price. The same firm is called the domestic firm in the market where consumption and production coincide, and the foreign firm in the market where it acts as a seller only. It is assumed that firms perceive each market as separate entities and thus that they have a 'segmented market perception'. This is an important assumption since it implies that a profitmaximizing firm having some monopolistic power over its product selects different prices if the price-elasticity of the demand for its product differs across markets. Product $i$ is thus completely characterized by its place of production, its location $x_{i}$ in the characteristics space, its price $\left(p_{i}\right.$ or $\left.q_{i}\right)$ and the shipping cost $t$.

In each market, the consumers' density is uniform and equal to $D$. Each consumer has a perfectly inelastic demand for one unit of the good and incurs transportation costs which are a quadratic function of the distance between the consumers' and the firm's location. The quadratic form ensures that a price equilibrium always exists [d'Aspremont et al. (1979)]. The full price paid by the consumer is then

$$
s_{i}+\left(x^{\mathrm{c}}-x_{i}\right)^{2},
$$

where $x^{\mathfrak{c}}$ is the consumer's location, $x_{i}$ the firm's location and $s_{i}$ is equal to $p_{i}$ when the consumer buys a domestic product or to $q_{i}+t$ when an imported product is bought.

Each firm's cost is

$$
C(Q)=F, \quad F>0 .
$$

This fixed cost function gives an L-shaped average total cost curve reaching asymptotically the zero marginal cost. The results are not affected by positive constant marginal costs. In the first part of the paper, $F$ can be interpreted as a fixed cost of production and, in the second part, as a location-specific sunk cost.

The market equilibrium depends on the product arrangement. By assumption, it is symmetric and interleaved. Firms are thus evenly spaced along the real line in both markets and each domestic producer competes directly with two foreign firms. Fig. 1 illustrates this configuration, where firms $1,2,3, \ldots$ are located at $L, 2 L, 3 L, \ldots$ and firms $-1,-2,-3, \ldots$ at $0,-L,-2 L, \ldots$, with $L$ representing the distance between any two adjacent firms.

The interleaved configuration is not just an ad hoc assumption, but an

${ }^{1}$ This assumption is very common in the recent literature on imperfect competition in international trade [see Markusen and Venables (1988) for a discussion]. Also, deviations from the law of one price to price discrimination across countries have empirical support [see, in particular, Giovannini (1988)]. 


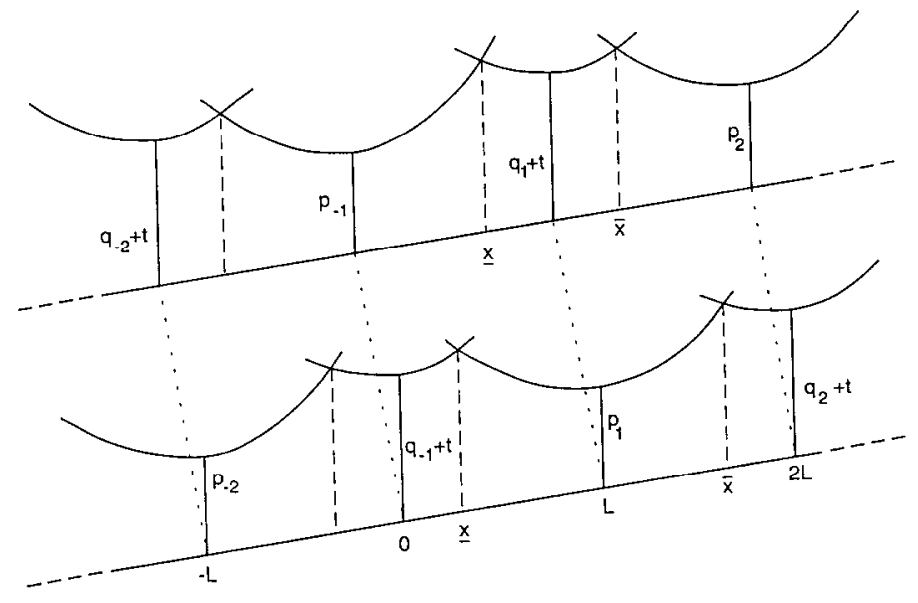

Fig. 1

equilibrium arrangement. However, the proof can be found elsewhere. ${ }^{2}$ The robustness of this firm's arrangement is not surprising since a firm always minimizes inter-firm rivalry. Hence, when a firm competes directly with two adjacent neighbors, it always prefers locating its production between two foreign firms. It makes this choice even if it also sells in the other market, since, as shown below, domestic sales are always more profitable than foreign sales in the presence of transport costs.

\section{Symmetric equilibrium with zero-profit}

In this section, the zero-profit equilibrium is derived for arbitrary intermarket shipping cost when firms choose prices simultaneously and when locations are symmetric and interleaved. Results of this simple game are then compared with those already existing in the literature.

First, assume that the distance between any two adjacent firms $(L)$ is exogenously given. Using standard methods in one-dimensional spatial models, the demand for product $i$ in its domestic market is ${ }^{3}$

\footnotetext{
${ }^{2}$ Schmitt (1990) shows that, in a similar model, the interleaved arrangement is the only possible symmetric equilibrium for all inter-market shipping costs consistent with trade between the two markets. Other symmetric arrangements, such as the matching arrangement (firms have the same set of locations in both markets) and the split arrangement (firms locate in separate halves of the markets depending on market of production), are not Nash equilibria for all $t$ consistent with trade in the corresponding arrangement.

${ }^{3}$ Demand for product $i$ is found by deriving first the location $\bar{x}$ of the consumer who is just indifferent between products $i$ and $(i+1)$ [i.e. $\left.s_{i}+\left(\bar{x}-x_{i}\right)^{2}=s_{i+1}+\left(x_{i+1}-\bar{x}\right)^{2}\right]$. Then, by finding the location $\underline{x}$ of the consumer indifferent between products $i$ and $(i-1)$, and finally hy calculating $D(\overline{\bar{x}}-x)$, where $D$ is the uniform consumer's density.
} 


$$
Q_{i}^{\mathrm{d}}\left(p_{i} ; q_{i-1}, q_{i+1}\right)=\frac{D}{2 L}\left(q_{i+1}+q_{i-1}+2 t-2 p_{i}+2 L^{2}\right) .
$$

Similarly, the demand for product $i$ in its foreign market is

$$
Q_{i}^{\mathrm{f}}\left(q_{i} ; p_{i-1}, p_{i+1}\right)=\frac{D}{2 L}\left(p_{i+1}+p_{i-1}-2\left(q_{i}+t\right)+2 I^{2}\right) .
$$

The problem of firm $i$ is then

$$
\max _{p_{i}, q_{i}} R_{i}\left(p_{i}, q_{i} ; p_{i-1}, p_{i+1}, q_{i-1}, q_{i+1}\right)=p_{i} Q_{i}^{\mathrm{d}}+q_{i} Q_{i}^{\mathrm{f}} .
$$

Two first-order conditions are obtained:

$$
\begin{aligned}
& q_{i+1}+q_{i-1}+2 t-4 p_{i}+2 L^{2}=0, \\
& p_{i+1}+p_{i-1}-4 q_{i}-2 t+2 L^{2}=0,
\end{aligned}
$$

where (4) corresponds to the choice of the optimal price of $i$ in its domestic market and (5) to the optimal price of $i$ in its foreign market.

Since the firm arrangement is symmetric and interleaved, all firms are identical.

It is easy to verify that there exists a unique set of equilibrium prices for the domestic products $(\hat{p})$ and for the foreign products $(\hat{q})$ such that $\hat{p}=p_{i}=p_{i+1}=p_{i-1}$ and $\hat{q}=q_{i}=q_{i+1}=q_{i-1}$. Using (4) and (5), these equilibrium prices are

$$
\begin{aligned}
& \hat{p}(L, t)=L^{2}+\frac{t}{3}, \\
& \hat{q}(L, t)=L^{2}-\frac{t}{3}
\end{aligned}
$$

From (6) and (7), the net import price is lower than the domestic price when $t>0$. Since the demand for imported products is more elastic then the demand for domestic products, the assumption of segmented market perception leads to reciprocal dumping [Brander and Krugman (1983)]. Note, however, that consumers' arbitrage across markets is never profitable since $\hat{q}+t-\hat{p}<t$.

Substituting (6) and (7) into (1) and (2), the demand for any product in the domestic $\left(\hat{Q}^{\mathrm{d}}\right)$ and in the foreign $\left(\hat{Q}^{\mathrm{f}}\right)$ market is

$$
\hat{Q}^{\mathrm{d}}(L, t, D)=\frac{D}{L}\left(L^{2}+\frac{t}{3}\right)
$$




$$
\hat{Q}^{\mathrm{f}}(L, t, D)=\frac{D}{L}\left(L^{2}-\begin{array}{l}
t \\
3
\end{array}\right) .
$$

Not surprisingly, inelastic consumers' demands make the total demand for any product independent of the shipping cost $t$.

The gross profit of the representative firm selling its product in both markets is thus equal to $\hat{p} \hat{Q}^{\mathrm{d}}+\hat{q} \hat{Q}^{\mathrm{f}}$, or

$$
\hat{R}(L, t, D)=\frac{D}{L}\left(L^{2}+\frac{t}{3}\right)^{2}+\frac{D}{L}\left(L^{2}-\frac{t}{3}\right)^{2} \text { for } \quad \frac{t}{L^{2}}<3
$$

If $a=t / L^{2}$, then it is apparent from (7) and (9) that exchanges between the two markets stop whenever the parameters of the model are such that $a \geqq 3$. It is intuitive that the greater $L$ is, the higher is the value of $t$ which stops trade between the two markets since $L$ is a good measure of the monopoly power of each firm. Two cases may then arise: one in which firms cannot trade but whose equilibrium prices still depend on forcign competition, and the other in which prices are completely independent of foreign competition.

The resulting equilibrium in the first case is a corner solution reminiscent of Salop (1979), which we call the prohibitive trade equilibrium, whereas, in the second case, we call it the autarkic equilibrium. One can show that complete isolation arises as soon as $\hat{p}(L, t)=4 L^{2}$ when adjacent (and domestic) firms are separated by $2 L$. This price requires $a=5$ in the symmetric and interleaved arrangement. It follows that the autarkic equilibrium occurs when $a \geqq 5$, in which case $\hat{p}(L, t)=4 L^{2}$. The prohibitive trade equilibrium occurs then when $3 \leqq a \leqq 5$, in which case $\hat{p}(L, t)=t-L^{2}$ since, even if no trade takes place, domestic firms must make sure that the foreign firm's mill price is never lower then their delivered price. In both cases, $\hat{Q}^{\mathrm{d}}(L, t, D)=2 D L$, so that

$$
\hat{R}(L, t, D)= \begin{cases}2 D L\left(t-L^{2}\right) & \text { when } 3 \leqq a \leqq 5 \\ 8 D L^{3} & \text { when } a \geqq 5\end{cases}
$$

To close the model, $L$ must be determined. Since there is free entry and the symmetric equilibrium locations result from a simultaneous choice by all the firms, the market equilibrium is reached when each identical firm earns no excess profits. ${ }^{4}$ Calling $\hat{L}$ the equilibrium distance between any two adjacent firms, it is determined by

$$
\hat{R}(\hat{L}, t, D)-F=0 .
$$

\footnotetext{
${ }^{4}$ The integer problem which may arise in a spatial model is disregarded since many firms are assumed to exist in each market.
} 
$L$ being now endogenous, it is possible to comparc the autarkic or the prohibitive trade equilibrium with the free-trade equilibrium.

Proposition I. A complete elimination of the prohibitive or the autarkic inter-market shipping cost between two identical markets leads to:

(i) a decrease in the number of domestic firms;

(ii) an increase in the scale of production of each remaining product;

(iii) an increase in product diversity in both markets;

(iv) an increase in price competition.

Proof. See the appendix.

These conclusions are identical to those derived in the intra-industry trade literature with non-spatial approaches [see, for instance, Krugman (1979); Dixit and Norman (1980); Lancaster (1980)]. Since lower transport costs lead to increased product diversity, to lower prices and to a higher volume of production for each individual good, production efficiency and average consumers' well-being are improved.

This shows that a spatial model with explicit multi-markets can be a useful tool even if it is extremely simple. It has further advantages; first, results are obtained with a model treating prohibitive trade and autarky as endogenous. Second, the marginal effects of changing the inter-market shipping cost can be easily evaluated from arbitrary rate; in particular, it can be checked that Proposition 1 also holds for small changes in $t .^{5}$ Even if these results are already quite instructive, additional conclusions about entry and multinationals can be obtained by modifying the game.

\section{Symmetric equilibrium with pure profits}

As recent developments in industrial organization have shown, the threat of entry affects existing firms' behavior and thus market structure [see Tirole (1988) for a survery]. With multi-markets, the role of entry is even more important since it might also affect the firm's organization of production. Spatial models provide a natural framework in which entry and organization of production can be investigated, but the game analyzed in the previous section where existing firms cannot be distinguished from new entrants, must be amended.

In order to identify clearly the role of entry, a two-stage game is necessary. In the first stage, a single entrant selects a location knowing that existing firms have fixed symmetric and interleaved locations, as illustrated in fig. 1.

\footnotetext{
${ }^{5}$ It can easily be established from (10) and (11) that $\mathrm{d} L / \mathrm{d} t \leqq 0$ whatever $t$; therefore, the effects of any change in $t$ always have the same sign. See Schmitt (1990) for different results using an ad valorem inter-market shipping cost.
} 
In the second stage, all firms (incumbents and the new one) announce simultaneously their prices. The perfect equilibrium of this two-stage game implies that the entrant correctly anticipates the effects of the entry on prices and profits, so that anticipation and realization of profits always coincide. The choice of entry location and the resulting free-entry equilibrium are then always rational for any given inter-market shipping cost. This game not only makes it possible to derive the entrant's optimal location, but also the condition under which any potential firm chooses to stay away from the market (free-entry equilibrium). Eaton and Wooders (1985) analyze the freeentry equilibrium in a single spatial model using this sophisticated entrant's behavior.

Here, the analysis is extended to the two-market environment with nontrivial effects on the optimal entrant's location.

Consider the entrant's possible strategies: either it locates between two existing firms and sells in both markets (trade strategy), or it chooses to sell only in the domestic market. When the inter-market shipping cost is low, the entrant's optimal choice is clearly the trade strategy, but when it is high, the entrant might find it more profitable to select the same location as an existing foreign firm (import replacement strategy) instead of the trade strategy since it knows that the foreign firm's lowest mill price is $t$ (since marginal cost is zero). The rate $t$ does not need to be prohibitive for this to happen. If incumbent firms were all multinationals, it is clear that the import rcplaccment stratcgy would not be credible. In this case, the incumbent firm's profit could be much higher. This suggests therefore that the multinational organization of production arises less to circumvent barriers to trade per se than to prevent the entrant's import replacement strategy from occurring.

The derivation of the entry behavior and of the perfect equilibrium of the two-stage game is not trivial. In effect, entry makes firms' locations asymmetric; since competition is localized, the post-entry price responses are stronger near the entrant's location than away from it. Therefore, each individual price response must be evaluated. The last stage of the game is discussed first paying special attention to the entrant's payoff, and then its choice of location is determined.

\subsection{Prices}

Suppose, without loss of generality, that the entrant locates at $h L$ in market 1 , where $0 \leqq h \leqq 1$. This corresponds to a location somewhere between products -1 and 1 in fig. 1 . Given the prices of its direct rivals, the demand faced by the entrant can be specified. In each market, the demand is divided into several segments, each valid for a specific entrant's price range: if the entrant's price is too high in market 1 for instance, it gets no share of that 
market. Decreasing its price, it first obtains a positive share of market 1 along with its two direct rivals (firm 1 and -1 ). With still lower prices, three cases can arise: the entrant's price is too low for firm -1 only to have a share of market 1; it is too low for firm 1 only; or, alternatively, for both firms to have a share of market 1 . Even lower entrant's prices would prevent additional firms, more distant from the entry location, from having a positive share of that market. For each entrant's price range, the corresponding segment of the demand function is different because it corresponds to a different set of the entrant's direct rivals. Similar demand functions also exist for the entrant in market 2 , as well as for all the other firms established in each market.

The determination of prices is not as complex as it looks. Note that a price equilibrium in pure strategies always exists for two reasons: first, the transportation cost function between firms and consumers is quadratic, which guarantees the continuity and the quasiconcavity of the profit function [d'Aspremont et al. (1979)]. Secondly, the main reason for non-existence of the price equilibrium is the firm's ability to undercut prices. In this model, such a possibility is reduced since each foreign firm's pricing strategy is limited by the extent of the inter-market shipping cost.

Consider now the game between two firms. If both are domestic (or foreign) firms, existing results [see d'Aspremont et al. (1979) or Gabszewicz and Thisse (1989)] show that the unique price equilibrium is given by $p_{j}^{*}=p_{i}^{*}=0$ (or $q_{j}^{*}=q_{i}^{*}=0$ ) when $x_{j}=x_{i}$, or by the equilibrium prices such that both firms have a positive share of the market when $x_{j} \neq x_{i}$. In other words, undercutting a rival of the same origin (domestic or foreign) forces one firm to adopt the same location as its rival since deviating from its location, while still undercutting it, always requires a strictly lower (and thus negative) price. Since this solution is well known, the analysis of the pricing equilibrium in each market can be restricted to the cases where firms do not try to undercut each other and where domestic firms attempt to undercut only rivals from a different origin.

Suppose that all firms, including the entrant, have a share of markets 1 and 2. Assuming $0<h<1$, the demands for the products available in market 1 , for instance, are

$$
\begin{aligned}
& Q_{1}^{\mathrm{d}}=\frac{D}{2(1-h) L}\left[p_{e}+(1-h)\left(q_{2}+t\right)-(2-h) p_{1}+(1-h)(2-h) L^{2}\right], \\
& Q_{e}^{\mathrm{d}}=\frac{D}{2(1-h) h L}\left[(1-h)\left(q_{-1}+t\right)+h p_{1}-p_{e}+h(1-h) L^{2}\right], \\
& Q_{-1}^{\mathrm{f}}=\frac{D}{2 h L}\left[p_{e}+h p_{-2}-(1+h)\left(q_{-1}+t\right)+h(1+h) L^{2}\right],
\end{aligned}
$$




$$
\begin{aligned}
& Q_{i}^{\mathrm{d}}=\frac{D}{2 L}\left[q_{i-1}+q_{i+1}+2 t-2 p_{i}+2 L^{2}\right], \quad i=\ldots,-4,-2,3,5, \ldots, \\
& Q_{j}^{\mathrm{f}}=\frac{D}{2 L}\left[p_{j-1}+p_{j+1}-2 q_{j}-2 t+2 L^{2}\right], \quad j=\ldots,-5,-3,2,4, \ldots .
\end{aligned}
$$

The problem of any firm $i(i=\ldots-2,-1, e, 1,2, \ldots)$ in the pricing stage is identical to (3)

$$
\max _{p_{i}, q_{i}} R_{i}\left(p_{i}, q_{i} ; p_{i-1}, p_{i+1}, q_{i+1}\right)=p_{i} Q_{i}^{\mathrm{d}}+q_{i} Q_{i}^{\mathrm{f}} .
$$

By substituting the relevant demand functions of markets 1 and 2 in the objective function, the gross profit of any firm can be written in terms of prices and of the entrant's location only. ${ }^{6}$

The post-entry equilibrium prices are found by solving the resulting set of first-order conditions in prices for markets 1 and 2. Since the marginal cost is contant, the set of first-order conditions can be solved separately for each market. For market 1 , these conditions are

$$
\begin{aligned}
& (1-h)\left(q_{-1}+t\right)+h p_{1}-2 p_{e}+h(1-h) L^{2}=0, \\
& p_{e}+(1-h)\left(q_{2}+t\right)-2(2-h) p_{1}+(1-h)(2-h) L^{2}=0, \\
& p_{e}+p_{-2}-(1+h)\left(2 q_{-1}+t\right)+h(1+h) L^{2}=0, \\
& q_{i-1}+q_{i+1}+2 t-4 p_{i}+2 L^{2}=0, \quad i=\ldots,-4,-2,3,5, \ldots, \\
& p_{j-1}+p_{j+1}-2 t-4 q_{j}+2 L^{2}=0, \quad j=\ldots,-5,-3,2,4, \ldots
\end{aligned}
$$

Conditions (18)-(20) represent the profit-maximizing conditions for the entrant, firm 1 and firm -1 , respectively, while (21) and (22) account for the remaining firms selling in market 1 . Note that (21) and (22) form two sets of simultaneous second-order difference equations: the first set is composed of (21) for $i=3,5,7, \ldots$, and (22) for $j=2,4,6, \ldots$, and the second set of (21) for $i=-2,-4, \ldots$, and (22) for $j=-3,-5, \ldots$. Using the properties of difference equations, section A.2 of the appendix shows that (21) and (22) can be reduced to

$$
\begin{aligned}
& q_{2}-b p_{1}-L^{2}(1-b)+\frac{t}{3}(1+b)=0, \\
& p_{-2}-b q_{-1}-L^{2}(1-b)-\frac{t}{3}(1+b)=0 .
\end{aligned}
$$

${ }^{6}$ To find the corresponding demand functions in market 2 , it is sufficient to replace all $p_{i}$ by $\left(q_{i}+t\right)$ and all $\left(q_{i}+t\right)$ by $p_{i}$ in $(13)-(17)$. 
The price equilibrium in the trade strategy conditional upon the entrant's location $(0<h<1)$ is found by solving (18)-(20), (23) and (24) for $\tilde{p}_{-2}, \tilde{q}_{-1}$, $\tilde{p}_{e}, \tilde{p}_{1}, \tilde{q}_{2}$ in market 1 , and by solving the corresponding equations in market 2 for $\tilde{q}_{-2}, \tilde{p}_{-1}, \tilde{q}_{e}, \tilde{q}_{1}, \tilde{p}_{2}$. Prices are unique such that

$$
\begin{aligned}
& \tilde{p}_{i}(L, h, t)=z_{i}(h) L^{2}+k_{i}(h) \frac{t}{3}, \\
& \tilde{q}_{i}(L, h, t)=z_{i}(h) L^{2}-k_{i}(h) \frac{t}{3},
\end{aligned}
$$

for $i=-2,-1, e, 1,2$. The functions $z_{i}(h)$ and $k_{i}(h)$ depend on the entrant's location $h .^{7}$ It can be checked that $z_{e}(h)<z_{i}(h)$ and $k_{e}(h) \leqq k_{i}(h)$ for $i=-1,1$ and $0<h<1$. In other words, entry unambiguously lowers prices in the neighborhood of entry. However, entry has only a local effect; this can be most easily seen by inspecting the other equilibrium prices [see (A.7) and (A.8)]. These prices are increasing in $i$ converging asymptotically to $\hat{p}$ or $\hat{q}$.

By substituting the equilibrium prices into the relevant demands, the demands for product $i$ in the domestic and foreign markets can be found. For the entrant, they are, respectively,

$$
\begin{aligned}
& \tilde{Q}_{e}^{\mathrm{d}}(L, h, D, t)=\frac{D}{2(1-h) h L}\left(z_{e}(h) L^{2}+k_{e}(h) \frac{t}{3}\right), \\
& \tilde{Q}_{e}^{\mathrm{f}}(L, h, D, t)=\frac{D}{2(1-h)} \overline{h L}\left(z_{e}(h) L^{2}-k_{e}(h) \frac{t}{3}\right) .
\end{aligned}
$$

${ }^{7}$ For $i=e$

$$
\begin{aligned}
& z_{e}(h)=\frac{1}{E}\left[h^{4}(-2 b+7)+\left(h^{3}+h^{2}\right)(4 b-14)+h(-6 b+21)\right] ; \\
& k_{e}(h)=\frac{1}{E}\left[3 h^{3}+h^{2}(3 b-15)-3 b+12\right] .
\end{aligned}
$$

For $i=1$

$$
\begin{aligned}
& z_{1}(h)=\frac{1}{E}\left[(1-h)\left(h^{2}(b-2)+h(-4 b+14)-3 b+9\right)\right] ; \\
& k_{1}(h)=\frac{1}{E}[(1-h)(h(-3 b+12)-3 b+9)] .
\end{aligned}
$$

For $i=-1$

$$
\begin{aligned}
& z_{1}(h)=\frac{1}{E}\left[h^{3}(h-2)+h^{2}(2 h-10)+h(-6 h+21)\right] ; \\
& k_{-1}(h)=\frac{1}{E}\left[h^{2}(3 b-12)+h(-3 b+15)-3 b+12\right],
\end{aligned}
$$

where $E=\left(h^{2}-h\right)(2 b-10)-3 b+12>0 ; 0<h<1$ and $b=2-3^{1 / 2}$. 
As noted above, the price equilibrium just described cannot hold for all parameter values. It holds as long as any domestic firm does not have an incentive to exclude any foreign firm from its domestic market and as long as foreign firms are willing to sell in this market. Suppose for the time being that domestic firms have no incentive to undercut foreign firms. Since markets are segmented, it follows that foreign frms agree to trade as long as $\tilde{q}_{i}>0$ and $\widetilde{Q}_{i}^{\mathrm{f}}>0$. In this problem, these two conditions are equivalent, so that, given (26), foreign firms trade as long as $a=t / L^{2}<\tilde{a}_{i}(h)$, where $\tilde{a}_{i}(h)=3\left[z_{i}(h) / k_{i}(h)\right]$. Using the expressions of footnote 7 , it can be checked that

$$
\frac{z_{-1}(h)}{k_{-1}(h)}<\frac{z_{e}(h)}{k_{e}(h)}<\frac{z_{1}(h)}{k_{1}(h)}
$$

for $0<h<1$. Hence, when the parameters $t$ and $L$ are such that $a<$ $3\left[z_{-1}(h) / k_{-1}(h)\right]$, every firm has a positive share of both markets. As $t$ increases (or $L$ decreases), firm $(-1)$, a foreign firm in market 1 , stops selling in this market before the entrant stops exporting to market 2, who in turn stops exporting before firm 1 does. As $t$ continues to rise, firms farther away from the entrant gradually cease to export in each other's market and no firm will be able to trade when a reaches its prohibitive value defined in the symmetric and interleaved equilibrium $(a=3)$. Of course as soon as firm $(-1)$ cannot have a positive share of market 1, (25) and (26) no longer describe the price equilibrium in that market. It is not very instructive to solve for all the equilibrium prices as $t$ rises (or $L$ decreases), but it is intuitive that they gradually increase to reach ultimately their prohibitive and their autarkic levels. Since we are mainly interested in the entrant's behavior, we concentrate our attention on the price equilibrium when firm $(-1)$ and/or the entrant cannot trade.

Case 1. $\quad \tilde{a}_{-1}(h) \leqq a<\tilde{a}_{e}(h)$; so that only firm $(-1)$ cannot trade in market 1 . Since markets are segmented, it follows that only the equilibrium in market 1 is affected. The entrant adopts one of two possible prices for its domestic product: for given $L$, either $t$ is sufficiently low so that the entrant must take into account firm $(-1)$ 's minimum mill price in that market, which forces the entrant to adopt a limit pricing behavior (i.e. a price such that $Q_{-1}^{f}=0$ when $\left.q_{-1}=0\right)$; or, $t$ is sufficiently high for the entrant to ignore firm $(-1)$ 's minimum import price in market 1 . In that case, it selects its optimal price as if firm $(-1)$ did not belong to its set of rivals.

Both entrant's prices can be found by modifying the first-order conditions (18)-(20), (23) and (24). If limit pricing holds, $q_{-1}=0 ; p_{-2}$ is then determined by (24). Since $Q_{-1}^{\mathrm{f}}=0$, this demand function defines a relationship between $p_{e}$ and $p_{-2}$ so that $p_{e}$ is uniquely determined. The other prices $\left(p_{1}\right.$ and $\left.q_{2}\right)$ are found by using (19) and (23). 
If the entrant ignores firm $(-1)$ in market 1 , the demands faced by the entrant and firm -2 must be modified accordingly. Using the same technique as above, the optimal prices for the entrant and its immediate rivals in market 1 are found by solving

$$
\begin{aligned}
& p_{e}+(1-h)\left(q_{2}+t\right)-2 p_{1}(2-h)+L^{2}(1-h)(2-h)=0, \\
& p_{1}(1+h)+p_{-2}(1-h)-4 p_{e}+2 L^{2}(1-h)(1+h)=0, \\
& p_{e}+\left(q_{-3}+t\right)(1+h)-2 p_{-2}(2+h)+L^{2}(2+h)(1+h)=0, \\
& q_{i+1}-b p_{i}-(1-b) L^{2}+\frac{t}{3}(1+b)=0, \quad i=-2,1 .
\end{aligned}
$$

Call $\tilde{\tilde{p}}_{i}^{m}$ and $\tilde{\tilde{q}}_{j}^{m}$ the profit-maximizing prices of the domestic and imported products, respectively, in market 1 , either when the entrant adopts a limit pricing behavior $(m=l)$ or when it ignores firm $(-1)(m=\mathrm{u})$. The set of equilibrium prices in market 1 is then

$$
\begin{aligned}
& \tilde{\tilde{p}}_{i}^{m}(L, h, t)=z_{i}^{\prime}(h) L^{2}+k_{i}^{\prime}(h) \frac{t}{3}, \quad i=\ldots-4,-2, e, 1,3, \ldots, \\
& \tilde{\tilde{q}}_{j}^{m}(L, h, t)=z_{j}^{\prime}(h) L^{2}-k_{j}^{\prime}(h) \frac{t}{3}, \quad j=\ldots-5,-3,2,4, \ldots,
\end{aligned}
$$

where $z_{i}^{\prime}(h), k_{i}^{\prime}(h), z_{j}^{\prime}(h)$ and $k_{j}^{\prime}(h)$ take one of two values depending on whether the entrant uses limit pricing $(m=l)$ or its unconstrained price $(m=\mathrm{u}){ }^{8}$ These prices have the same characteristics as in the trade strategy: they are lower around entry and converge to their pre-entry equilibrium values as one moves away from the entrant's location. Of course, the entrant

${ }^{8}$ For instance,

$$
\begin{aligned}
& z_{e}^{\prime}(h)= \begin{cases}-h(2+h-b), & \text { when } \tilde{\tilde{p}}_{e}=\tilde{\tilde{p}}_{e}^{l}, \\
\left(1 / E^{\prime}\right)\left[h^{4}(5-b)+h^{2}(8 b-31)+26-7 b\right], & \text { when } \tilde{\tilde{p}}_{e}=\tilde{\tilde{p}}_{e}^{\mathrm{u}}\end{cases} \\
& k_{e}^{\prime}(h)= \begin{cases}3(1+h)-h(1+b), & \text { when } \tilde{\tilde{p}}_{e}=\tilde{\tilde{p}}_{e}^{l}, \\
\left(1 / E^{\prime}\right)\left(h^{2}-1\right)(2 b-7), & \text { when } \tilde{\tilde{p}}_{e}=\tilde{\tilde{p}}_{e}^{\mathrm{u}} ;\end{cases} \\
& z_{1}^{\prime}(h)= \begin{cases}\left(1 / E^{\prime \prime}\right)(3-b)(1-2 h), & \text { when } \tilde{\tilde{p}}_{e}=\tilde{\tilde{p}}_{e}^{l} \\
\left(1 / E^{\prime}\right)\left[h^{3}(2-b)+\left(h^{2}+h\right)(4 b-14)+26-7 b\right], & \text { when } \tilde{\tilde{p}}_{e}=\tilde{\tilde{p}}_{e}^{\mathrm{u}}\end{cases} \\
& k_{1}^{\prime}(h)= \begin{cases}\left(1 / E^{\prime \prime}\right)(5-b), & \text { when } \tilde{\tilde{p}}_{e}=\tilde{\tilde{p}}_{e}^{l}, \\
\left(1 / E^{\prime}\right)\left[h^{2}(b-8)+h(3 b-6)+14-4 b\right], & \text { when } \tilde{\tilde{p}}_{e}=\tilde{\tilde{p}}_{e}^{u},\end{cases}
\end{aligned}
$$

where $E^{\prime}=h^{2}(b-8)+26-7 b ; E^{\prime \prime}=2(2-h)-h(1-h)$ and $b=2-3^{1 / 2}$. Also, when $h=0, z_{1}^{\prime}(h)=$ $z_{-2}^{\prime}(h), k_{1}^{\prime}(h)=k_{-2}^{\prime}(h), z_{2}^{\prime}(h)=z_{3}^{\prime}(h), k_{2}^{\prime}(h)=k_{-3}^{\prime}(h)$ and so on. 
adopts its unconstrained price only when it does not allow firm $(-1)$ to have a share of market 1 . Hence,

$$
\tilde{\tilde{p}}_{e}=\min \left(\tilde{\tilde{p}}_{e}^{l}, \tilde{\tilde{p}}_{e}^{\mathrm{u}}\right) \text {. }
$$

When $\tilde{\tilde{p}}_{e}$ holds, the demand faced by the entrant no longer depends on $q_{-1}$ as in (14). Substituting the relevant prices in $Q_{e}^{\mathrm{d}}\left(p_{-2}, p_{e}, p_{1}\right)$, the equilibrium demand for the entrant's product in market 1 is ${ }^{9}$

$$
\tilde{\tilde{Q}}_{e}^{\mathrm{d}}(L, h, D, t)= \begin{cases}\frac{D}{2(1-h)(1+h) L}\left(z_{e}^{\prime \prime}(h) L^{2}+k_{e}^{\prime \prime}(h) \frac{t}{3}\right) & \text { when } \tilde{\tilde{p}}_{e}=\tilde{\tilde{p}}_{e}^{l}, \\ \frac{D}{(1-h)(1+h) L}\left(z_{e}^{\prime}(h) L^{2}+k_{e}^{\prime}(h) \frac{t}{3}\right) & \text { when } \tilde{\tilde{p}}_{e}=\tilde{\tilde{p}}_{e}^{\mathrm{u}} .\end{cases}
$$

Case 2. $\quad \tilde{a}_{e}(h) \leqq a<\tilde{a}_{1}(h)$; so that firm $(-1)$ and the entrant cannot trade. Since markets are segmented and variable costs are absent (or constant), the equilibrium in market 1 as just described still holds. The equilibrium in market 2 is now affected but since the entrant no longer has a share of this market, its behavior is not altered, hence we omit to report it.

Since it can be checked that the entrant has no incentive to exclude firm $(-1)$ from market 1 when firm $(-1)$ can trade in that market [i.e. $\tilde{p}_{e} \tilde{Q}_{e}^{\mathrm{d}} \geqq \tilde{\tilde{p}}_{e}^{l} \widetilde{Q}_{e}^{\mathrm{d}}$ for $\left.a \leqq \tilde{a}_{-1}(h)\right]$, and since a similar conclusion holds for firm $(-1)$ with respect to the entrant in market 2 at $a=\tilde{a}_{e}(h)$, the equilibrium entrant's gross payoff for $0 \leqq h<1$ and all $t$ and $L$ satisfying $a<\tilde{a}_{1}(h)$ is

$$
R_{e}(L, h, D, t)= \begin{cases}\tilde{p}_{e} \widetilde{Q}_{e}^{\mathrm{d}}+\tilde{q}_{e} \widetilde{Q}_{e}^{\mathrm{f}} & \text { if } a<\tilde{a}_{-1}(h), \\ \tilde{\tilde{p}}_{e} \tilde{\tilde{Q}}_{e}^{\mathrm{d}}+\tilde{q}_{e} \tilde{Q}_{e}^{\mathrm{f}} & \text { if } \tilde{a}_{-1}(h) \leq a<\tilde{a}_{e}(h), \\ \tilde{\tilde{p}}_{e} \tilde{\tilde{Q}}_{e}^{\mathrm{d}} & \text { if } \tilde{a}_{e}(h) \leqq a<\tilde{a}_{1}(h) .\end{cases}
$$

Of course, the price equilibrium and the entrant's payoff could also be found for $t$ and $L$ such that $a \geqq \tilde{a}_{1}(h)$. Note, however, that they would not add much understanding of the entrant's behavior since not only does the equilibrium in market 2 have no effect on its behavior since it cannot trade in this market, but in addition the equilibrium in market 1 has little effect on the entrant since competition is localized and only firms relatively far from

${ }^{9}$ The demand function

$$
Q_{e}^{\mathrm{d}}\left(p_{-2}, p_{e}, p_{1}\right)=\frac{D}{2 L(1-h)(1+h)}\left[p_{1}(1+h)+p_{-2}(1-h)-2 p_{e}+2 L^{2}(1-h)(1+h)\right] .
$$

When $\quad \tilde{\tilde{p}}_{c}=\tilde{\tilde{p}}_{c}^{\prime}, \quad z_{c}^{\prime \prime}(h)=\left(1 / E^{\prime \prime}\right)\left[2(7-2 b)+h^{2}(3 b-11)+h(3-b)\right] \quad$ and $\quad k_{c}^{\prime \prime}(h)=\left(1 / E^{\prime \prime}\right)[2(2 b-7)+$ $\left.h^{2}(9-3 b)+h(b-5)\right]$. 
the entrant's location stop trading when $a \geqq \tilde{a}_{1}(h)$. When no firms can trade, the price equilibrium and the entrant's payoff can easily be found since Eaton and Wooders' (1985) results apply, both when $a \geqq 5$ and $3 \leqq a \leqq 5$. As in section 3, however, equilibrium prices and profits are lower in the prohibitive trade equilibrium than in the autarkic equilibrium since, in the former case, existing domestic firms in each market must take into account the minimim price of foreign firms.

The entrant's choice of location can now be analyzed in detail.

\subsection{Location}

The entrant's optimal location $h$ is determined by the first-order condition $\partial R_{e} / \partial h=0$. Before specifying the optimal entrant's location for arbitrary $t$ and $L$, we concentrate our attention on those values for which either all firms trade, or firm $(-1)$ only does not trade. Since the entrant's location is already interesting in these two cases, we present the results in two propositions. We then extend the analysis to arbitrary $t$ and $L$.

Suppose first that all the firms trade in each other's market.

Proposition 2. Given the interleaved arrangement, the entrant's profitmaximizing location in the trade strategy depends on the shipping cost $t$ and on the distance between established firms $L$ : the entrant locates half-way between a foreign and a domestic firm when $a=0$, and it locates closer to a foreign firm's location as a increases.

Proof. See the appendix.

This result has an intuitive explanation. When $a=0$, existing firms cannot be distinguished from each other, so that $h=1 / 2$ is clearly the entrant's optimal location [see Eaton and Wooders (1985)]. In particular, an entrant never chooses the same location as an existing firm since it takes into account the effect of its location on prices. When $a$ rises (because either $t$ increases or $L$ decreases with $t>0$ ), the entrant has an incentive to locate relatively closer to a foreign firm in both markets, since the consumer's price of imported products increases relative to the price of domestic products. However, the force determining the entrant's location in its domestic market is stronger than that acting in its foreign market since domestic sales are more profitable than foreign sales.

The curve $e f g$ in fig. 2 illustrates the entrant's optimal location when all firms have positive shares of both markets. It shows that as $t$ increases relative to $L, h$ decreases to reach 0.33 , below which the second-order condition $\partial^{2} R_{e} / \partial h^{2}$ is no longer satisfied ( $a=0.823$ ).

Entry dramatically increases price competition, but its effects are extremely 


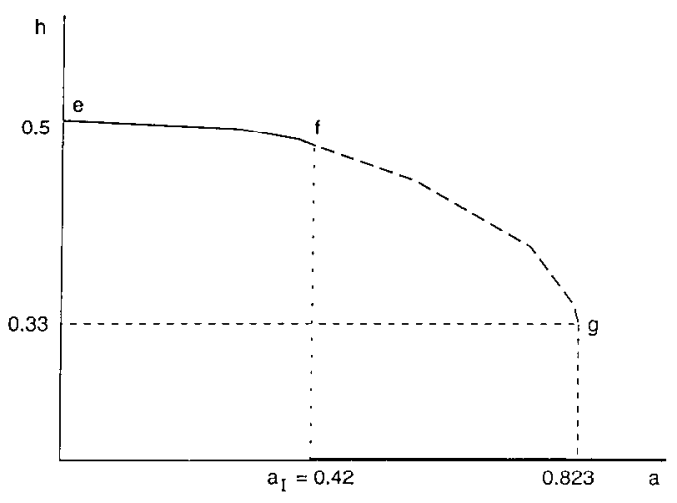

Fig. 2

localized. This can be appreciated by inspecting the post-entry equilibrium prices [given by (25), (26) and footnote 7]. At $t=0$, the pre-entry markup of each firm is equal to $L^{2}$. Dividing by $L^{2}$ the post-entry markups of the entrant and of firms 1,2,3 and 4, the ratios $0.387,0.524,0.966$ and 0.99 are obtained. Hence, existing firms adjacent to the new entrant have their markups reduced by half, but, from firm 4 on, the market is very little affected by entry.

The cffcet is more dramatic when $a$ rises. $\Lambda$ s the entrant locates closer to the imported product, it captures an increasing share of its market. The foreign firm reponds by decreasing its net price, but its consumers' mill price remains higher than the entrant's mill price $\left(\tilde{q}_{-1}+t>\tilde{p}_{e}\right)$. This explains why, for some values of $t$ and $L$, the entrant can still have a share of both markets, while firm $(-1)$ cannot.

Consider now the entrant's optimal location when firm $(-1)$ cannot trade.

Proposition 3. When firm (-1) cannot trade, the entrant's optimal location is always $h=0$ whether it adopts a limit price or an unconstrained price.

The proof is long and tedious, but the results are again intuitive. Suppose first that the entrant, located in market 1 , sells only in this market at the limit price. Its optimal location depends on $\partial R_{e} / \partial h=\left(\partial p_{e} / \partial h\right) Q_{e}^{\mathrm{d}}+p_{e}\left(\partial Q_{e}^{\mathrm{d}} / \partial h\right)$. Not surprisingly, $\partial p_{e} / \partial h<0$ for all feasible $h$ : the entrant must lower its price as $h$ rises since it must make sure that its delivered price at firm $(-1)$ 's location $(h=0)$ is never higher than the foreign firm's minimum mill price. As a result, $p_{e}$ is quite elastic with respect to $h$. The demand effect $\left(\partial Q_{e}^{\mathrm{d}} / \partial h\right)$ is positive, but small. Hence, $\partial R_{e} / \partial h<0$, which leads the entrant always to choose the corner solution $h=0$.

Suppose now that the entrant also exports to market 2. This tends to pull 
the entrant's location away from $h=0$, since it wants to avoid being in direct competition with firm $(-1)$ in its domestic market. However, this effect is never strong enough to induce the entrant to adopt another location than $h=0$. This is not surprising since the entrant's domestic market is much bigger than its foreign market when firm $(-1)$ is excluded from market 1 and since, with positive $t$, domestic sales are more profitable than foreign ones.

Finally, suppose that the entrant can choose its unconstrained price, ignoring firm $(-1)$ in market 1 . The entrant's problem is now simply to find an optimal location when the two adjacent competitors are symmetric domestic firms. Not surprisingly, profits are maximized at the middle location $h=0$. Again, possible gains by exporting are not large enough to induce the entrant to alter its location.

Note that Proposition 3 also holds when several (or all) existing firms cannot trade since, with (29), firm $(-1)$ is necessarily among them. Hence, whatever $t, L$ or the number of existing firms, the entrant adopts one of two strategies: either $0<h \leqq 1 / 2$ and it trades along with the other firms, or $h=0$ and it sells only in its domestic market. The strong discontinuity in the entrant's location occurs when profits on exports no longer compensate for the opportunity cost of not maximizing profits in the domestic market alone. The entrant's optimal location $\left(h^{*}\right)$ is thus the solution of

$$
R_{e}^{*}\left(h^{*} ; L, D, t\right)=\max \left\{R_{e}(h ; L, D, t) ; R_{e}(h=0 ; L, D, t)\right\} .
$$

Define $a_{I}$ as the ratio $t / L^{2}$ such that the entrant is indifferent between $h>0$ and $h=0$, [i.e. $\left.R_{e}(h>0 ; L, D, t)=R_{e}(h=0 ; L, D, t)\right]$.

Proposition 4. There exists an entrant's optimal location for any feasible value of the parameters $(0 \leqq a \leqq 5)$. The entrant adopts the trade strategy $\left(h^{*}>0\right)$ whenever $a<a_{1}$. It selects the foreign firm's location $h^{*}=0$ whenever $a_{I}<a \leqq 5$. Since the entrant switches strategy and adopts $h^{*}=0$ at a value of the parameters that would still allow this foreign firm to have a share of the market in the trade strategy $\left(a_{1}<\tilde{a}_{-1}(h)\right)$, the entrant replaces imports.

Proof. See the appendix.

The entrant's optimal location, including the discontinuity at $a_{I}$, is illustrated in fig. 2. It shows that the trade strategy is more profitable only when $a<a_{I}$ so that the import replacement strategy is optimal over a wide range of parameters. ${ }^{10}$

This result is interesting because it shows that adopting the same location as an existing firm is consistent with rational foresight even if firms take into

\footnotetext{
${ }^{10}$ The import replacement strategy $\left(h^{*}=0\right)$ can be further divided into two ranges of intermarket shipping cost: one in which the entrant adopts the limit price $\tilde{\tilde{p}}_{c}=t$ and the other in which $\overline{\hat{p}}_{\mathrm{e}}<t$.
} 
account the effect of their choice on prices and even if there are several existing firms. This is only possible because the inter-market shipping cost creates a disadvantage to imported products with respect to domestic products by increasing the minimum price at which they can be sold. The inter-market shipping cost introduces therefore one aspect of vertical differentiation among products.

Note also that the entrant's strategies do not depend on the segmented market assumption. Suppose firms must choose a single producer's price for the two markets. It remains true that the inter-market shipping cost makes imported products more expensive than domestic ones. Hence, an entrant also has an incentive to locate closer to a foreign firm than to a domestic firm. The incentive to replace imports also remains since the entrant knows that, if an established foreign firm adopts a low price to discourage entry, it lowers its profit in its domestic market as well. If anything, the constraint of a single price tends to favor the import replacement strategy, provided that an equilibrium exists.

\subsection{Free-entry equilibrium and multinationals}

It is now straightforward to close the model by finding the free-entry equilibrium; that is, the condition for which entry is unprofitable. Because of the asymmetry between existing and potential firms, this condition depends on the entrant's profit only. Knowing the entrant's optimal strategy and $t$, the distance bewteen two adjacent firms $(L)$ in the symmetric interleaved equilibrium can be calculated such that entry is unprofitable. Since profit is a positive function of $L$, the maximum distance, called $\bar{L}$, between two adjacent firms is found with

$$
R_{e}^{*}\left(\bar{L}, h^{*}, D, t\right)-F=0 .
$$

The specific functions depend, of course, on the strategy adopted by the cntrant, and thus on the parameters of the model. ${ }^{11}$ The solutions in the

\footnotetext{
${ }^{11}$ The entrant's gross profit relevant to determine $\bar{L}$ is given by (32). Hence, when $h^{*} \neq 0$ is optimal and $a<\bar{a}{ }_{1}(h), \bar{l}$ is then the positive root of

$$
z_{e}^{2}(h) L^{4}-h(1-h) \frac{F}{D} L+k_{e}(h) \frac{t^{2}}{9}=0 .
$$
}

When $h^{*}=0$ is optimal and $a<\tilde{a}_{1}(h), \bar{L}$ is the positive root of

and

$$
L^{2}-\left(\begin{array}{c}
4-b \\
7-2 b
\end{array}\right){ }_{D}^{F} \frac{1}{t} L-\frac{l}{3}=0, \quad \text { when } \tilde{\tilde{p}}_{e}=\tilde{\tilde{p}}_{e}^{l}
$$

$$
L^{4}+\frac{2}{3}\left(\begin{array}{c}
2-b \\
7-2 b
\end{array}\right) t L^{2}-\frac{F}{D} L+\left(\begin{array}{c}
2-b \\
7-2 b
\end{array}\right)_{9}^{2} t^{2}=0, \quad \text { when } \tilde{\tilde{p}}_{e}=\tilde{\tilde{p}}_{e}^{\mathrm{u}}
$$

When $a=5$, Eaton and Wooders' (1985) result applies. 


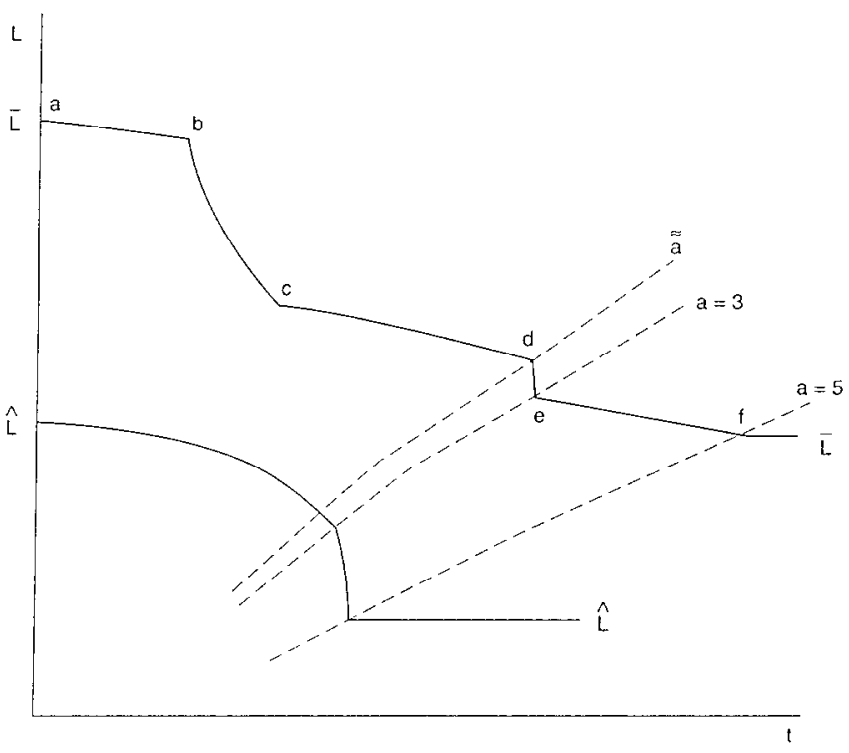

Fig. 3

$(L, t)$ space are shown in fig. 3 , which is drawn for $F=D=1$. The locus $\bar{L}$ is composed of several sections: $(a-b)$ corresponds to the trade case; $(b-c)$ to the import replacement strategy with limit pricing; $(c-d)$ to the same strategy with unconstrained price and $(e-f)$ to the equilibrium with prohibitive trade and autarky, ${ }^{12}$

$\bar{L}$ is negatively sloped because, as $t$ rises, price competition decreases, increasing firms' profits. Since the free-entry equilibrium is derived for a given shipping cost, a higher $t$ requires a larger number of existing firms, and thus a smaller distance between them.

Any $(L, t)$ pair below the locus $\bar{L}$ and consistent with the post-entry equilibrium represents a free-entry equilibrium solution, where no entry can take place and existing firms earn excess returns. This can easily be illustrated in fig. 3 by introducing the zero-profit condition (12). Since $\bar{L}>\hat{L}$ for any inter-market shipping cost (if $D>0$ and $F<\infty$ ) and since profit is a

\footnotetext{
${ }^{12}$ The sharp drop in $\bar{L}$ for $\tilde{\tilde{a}} \leqq a \leqq 3$ corresponds to the sudden decrease in the number of products sold in market 1 . Because competition is extremely localized around the entrant, the shipping cost $t_{2}$ which prevents firm 2 (or firm -3) from trading in market 1 when $h^{*}=0$ (and which defines $\tilde{a}$ ). also corresponds approximately to the rate at which every other existing firms stops trading.
} 
positive function of $L$, existing firms enjoy pure profits in the free-entry equilibrium.

The last result to establish is that, depending on the additional cost of producing abroad, existing firms may have a strong incentive to adopt a multinational organization of production in order to prevent the import replacement strategy from occurring.

Fig. 3 shows clearly that entry has a strong competitive effect when established firms trade. The minimum number of firms (or products) consistent with no entry must increase dramatically as soon as the entrant's optimal strategy is to replace imports (bcdef). The reason is that, since import replacement is profitable, the only way to stop entry is to reduce the size of the entrant's potential market such that its set-up cost is not covered. But doing so is clearly detrimental to existing firms since products become closer substitutes. Hence, if the entrant could be forced to choose $h^{*} \neq 0$ as an optimal location, established firms' pure profits in the free-entry equilibrium would not decrease by as much as in the import replacement strategy. The question is then whether existing firms can secure these additional rents or, equivalently, whether they can make the import replacement strategy non-credible. The multinational organization of production is one way of achieving this result because, by committing resources to the foreign market (capacity of production), a foreign firm presents itself now as a domestic firm. Price undercutting can no longer be successful since existing firms have the same minimum price as the new firm.

Suppose therefore that all existing firms, except the entrant, have established foreign production. The entrant's optimal location is now half way between two incumbents $\left(h=\frac{1}{2}\right)$ irrespective of the inter-market shipping cost. Except for the fact that the entrant might still trade, Eaton and Wooders' (1985) results hold. Then, it can be shown that

$R_{e}\left(h^{*}=\frac{1}{2} ; L, D, t\right)= \begin{cases}\frac{D L^{3}}{2}\left(\frac{\alpha}{\beta}\right)^{2}+\frac{D}{2 L}\left[L^{2}\left(\frac{\alpha}{\beta}\right)-t\left(\frac{\alpha-b}{\beta}\right)\right]^{2}, & \text { if } 0 \leqq a \leqq[\alpha /(\alpha-b)], \\ \frac{D L^{3}}{2}\left(\frac{\alpha}{\beta}\right)^{2}, & \text { if } a \geqq[\alpha /(\alpha-b)],\end{cases}$

where $\alpha=16-5 b, \beta=20-4 b, b=2-3^{1 / 2}$ and $a=t / L^{2}$. The critical value $a=[\alpha /(\alpha-b)]$ represents the combinations of $t$ and $L$ preventing the entrant from trading when all established firms produce in both markets.

It is easy to establish from (33) that $\mathrm{d} L / \mathrm{d} t \geqq 0$ for all values of $t$ and $L$, so that the maximum distance between established firms which prevents a potential firm from entering $(\bar{L})$ is never smaller when existing firms are multinationals than when they trade. This must happen because, at $t=0$, the entrant's expected profit is the same whether existing firms trade or produce 
in both markets, but, as $t$ rises the entrant's expected profit must decrease since its share of the foreign market gets smaller and its share of the domestic remains the same. This implies that established firms can sell lower substitute products without attracting entry when they are organized as multinationals than when they trade. This does not necessarily imply, however, that they earn higher pure profit with the multinational organization of production, since it depends also on the additional cost of producing abroad.

Of course, if there is no additional cost of producing in more than one market, established firms unambiguously prefer organizing themselves as multinationals rather than to concentrate production and trade. If firms must incur additional (fixed) cost to establish production in another market, it is obvious that the larger this cost, the lower is the value of $t$ from which it becomes more profitable to trade rather than to act as a multinational. The effect of restricting the entrant's optimal location at $h=\frac{1}{2}$ is non-trivial since, when $F / D=1$ for instance, it can be calculated that, in the free-entry equilibrium, firm $(-1)$ earns more than twice the gross profit it would earn when the entrant finds it credible to replace its imports. Hence, in this case the fixed cost of producing in another market must be strictly larger than that in the domestic market for established firms to prefer always trading rather than organizing themselves as multinationals. Thus, depending on the additional cost of producing abroad, existing firms have a strong incentive to organize themselves as multinationals. Barriers to trade per se have much less influence on this incentive than the potential firm's behavior they imply.

\section{Conclusion}

This paper shows that an explicit two-market spatial model is a useful tool to analyze specific economic problems. Not only does this approach replicate accepted results based on other methods of derivation, but in addition, the market equilibrium for arbitrary intermarket shipping cost can be characterized and entry behavior carefully investigated. Since one possible application of this model is the effect of bilateral trade liberalization, which generally occurs from non-prohibitive barriers to trade, it is useful to have tools to analyze its effects on firms' behavior and market equilibrium whatever the initial tariff rate.

Entry location is shown to depend strongly on the transport cost for tariff), especially when it is low. In particular, an entrant finds it optimal to adopt the same location as a foreign firm over a wide range of feasible transport costs, even if there are several existing firms. This threat of import replacement constitutes a strong motive for incumbent firms to adopt a multinational organization of production if the additional cost of producing abroad is not too high. Hence, this result suggests that it is much less the 
barriers to trade per se that makes foreign production attractive than the import replacement strategy they imply if they do not organize themselves as multinationals.

The major drawbacks of finding the optimal entrant's location is that it requires quite sophisticated methods. There is, however, no simple approach to analyze entry when locations of the existing firms are fixed, since the entry decision must be based on profits that can be realized. This requires computation of the post-entry equilibrium, and thus of the price response of the existing firms. Localized competition, which characterizes onedimensional spatial models, adds another difficulty since it introduces asymmetries in these price responses.

Whcreas the zcro-profit cquilibrium implies that, in a dynamic context, existing firms relocate in response to entry, entry behavior can only be understood when incumbent firms have fixed location. Whether firms have free or fixed locations depends more on the structural characteristics of industries (some industries mainly incur investments that still have market value when the activity stops, whereas other industries mostly incur sunk costs) than on a distinction between short- and long-run equilibrium [see Eaton and Lipsey (1980)]. This suggests that by analyzing the role of entry, we capture important features of the market structure of many industries operating in multi-markets.

\section{Appendix}

\section{A.I. Proof of Proposition 1}

Call $\hat{L}^{\mathrm{F}}$ the equilibrium distance when $t=0, \hat{L}^{\mathrm{P}}$ when trade is prohibitive $(a=3)$ and $\hat{L}^{\mathrm{A}}$ in the autarkic equilibrium $(a=5)$. Using (12) with (10) or (11), $\hat{L}^{\mathrm{F}}=(F / 2 D)^{1 / 3} ; \hat{L}^{\mathrm{P}}=(F / 4 D)^{1 / 3}$ and $\hat{L}^{\mathrm{A}}=(F / 8 D)^{1 / 3}$. Hence, $\frac{1}{2} \hat{L}$;

(i) holds since $\hat{L}^{\mathrm{F}}>\hat{L}^{\mathrm{P}}>\hat{L}^{\mathrm{A}}$ and the number of domestic firms is given by

(ii) holds since the firm's total production in the three equilibria is equal to $2 D L$ and $\hat{L}^{\mathrm{F}}>\hat{L}^{\mathrm{P}}>\hat{L}^{\mathrm{A}}$;

(iii) holds since $\hat{L}^{\mathrm{F}}<2 \hat{L}^{\mathrm{P}}$ and $\hat{L}^{\mathrm{F}}<2 \hat{L}^{\mathrm{A}}$;

(iv) holds since $\hat{p}(a=0)=(F / 2 D)^{2 / 3}<\hat{p}(a=3)=2(F / 4 D)^{2 / 3}<\hat{p}(a=5)=$ $4(F / 8 D)^{2 / 3}$.

\section{A.2. Solving second-order difference equations}

We concentrate first on firms $2,3,4, \ldots$ in market 1 . Using standard methods for solving simultaneous second-order difference equations [see Chiang (1984)], the particular integrals are equal to the equilibrium prices in the symmetric interleaved arrangement $[\hat{p}$ and $\hat{q}$ as given by (6) and (7)]. 
The complementary functions are found by assuming that $q_{j}=n b^{j}$ and $p_{i}=m b^{i}$, so that the reduced versions of (21) and (22) are

$$
\begin{aligned}
& m\left(b^{2}+1\right)-4 n b=0, \\
& -4 m b+n\left(b^{2}+1\right)=0 .
\end{aligned}
$$

To avoid the trivial solutions $m=n=0$, the determinant of the coefficient martix formed by (A.1) and (A.2) is set to zero. The resulting characteristic equation is

$$
\left(b^{2}+1\right)^{2}-16 b^{2}=0,
$$

which has roots $b_{1}, b_{2}=2 \pm 3^{1 / 2}$ and $b_{3}, b_{4}=-\left(2 \pm 3^{1 / 2}\right)$. Assume first that $b_{1}$ and $b_{2}$ are the relevant roots. Substituting them into (A.1) and (A.2) gives unique solutions $m=n=A_{1}$ associated with $b_{1}$ and $m=n=A_{2}$ associated with $b_{2}$, where $A_{1}$ and $A_{2}$ are arbitrary constants depending on the initial conditions of the system. Taking into account the particular integrals $\hat{p}$ and $\hat{q}$, the general solutions for market 1 can be written as

$$
\begin{aligned}
& p_{i}=\hat{p}+A_{1} b_{1}^{i-1}+A_{2} b_{2}^{i-1}, \quad i=1,3,5, \ldots, \\
& q_{j}=\hat{q}+A_{1} b_{1}^{j-1}+A_{2} b_{2}^{j-1}, \quad j=2,4,6, \ldots,
\end{aligned}
$$

where $b_{1}>1$ and $0<b_{2}<1$. For $A_{1}>0, p_{i}$ and $q_{j}$ increase without bound when $i$ and $j$ rise. Bounded prices and consumers' income require therefore $A_{1}=0$.

At the initial conditions $i=1$ and $j=2$,

$$
\begin{aligned}
& p_{1}+\hat{p}+A_{1}+A_{2}, \\
& q_{2}=\hat{q}+A_{1} b_{1}+A_{2} b_{2} .
\end{aligned}
$$

Solving for $A_{1}$ and $A_{2}$,

$$
\begin{aligned}
& A_{1}=\left(\frac{1}{b_{1}-b_{2}}\right)\left(q_{2}-\hat{q}-b_{2}\left(p_{1}-\hat{p}\right)\right), \\
& A_{2}=\left(\frac{1}{b_{1}-b_{2}}\right)\left(b_{1}\left(p_{1}-\hat{p}\right)-\left(q_{2}-\hat{q}\right)\right) .
\end{aligned}
$$

Since $A_{1}=0$, and setting $b=b_{2}$,

$$
q_{2}=\hat{q}+b\left(p_{1}-\hat{p}\right) .
$$


It can be shown that, when $b_{3}$ and $b_{4}$ are the relevant roots, $b_{4}=-b_{2}$ and $A_{4}=A_{2}$ leading to the same solutions as when the roots are $b_{1}$ and $b_{2}$.

For firms $-2,-3, \ldots$ in market 1 , a similar exercise leads to

$$
\hat{p}_{-2}=\hat{p}+b\left(q_{-1}-\hat{q}\right) \text {. }
$$

Hence, (21) and (22) can be reduced to (A.5) and (A.6) and, with $\hat{p}$ and $\hat{q}$, to (23) and (24).

Since the product arrangement is interleaved, it is obvious that in market 2, the corresponding price relationships to (A.5) and (A.6) are, respectively,

$$
\begin{aligned}
& p_{2}=\hat{p}+b\left(q_{1}-\hat{q}\right), \\
& q_{-2}=\hat{q}+b\left(p_{-1}-\hat{q}\right) .
\end{aligned}
$$

Any other price in the post-entry equilibrium can easily be calculated. For instance, knowing (A.5), $A_{2}=\left(p_{1}-\hat{p}\right)$ so that (A.3) and (A.4) become

$$
\begin{aligned}
& p_{i}=\hat{p}+\left(p_{1}-\hat{p}\right) b^{i \quad 1}, \quad i=3,5, \ldots, \\
& q_{j}=\hat{q}+\left(p_{1}-\hat{p}\right) b^{j-1}, \quad j=4,6, \ldots
\end{aligned}
$$

\section{A.3. Optimal entrant's location in the trade strategy}

This result can be shown in two steps. First, with (25), (26), (27) and (28), $\partial R_{e} / \partial h=0$ can be expressed as $L^{4} f(h)+\left(t^{2} / 9\right) g(h)=0$, or, with $a=t / L^{2}$, as

$$
a^{2} g(h)+9 f(h)=0
$$

where

$$
\begin{aligned}
f(h) & =0, \quad \text { for } h=0, h=\frac{1}{2}, h=1, \\
& >0, \quad \text { for } 0<h<\frac{1}{2}, \\
& <0, \quad \text { for } \frac{1}{2}<h<1,
\end{aligned}
$$

and

$$
\begin{aligned}
g(h) & =0, \quad \text { for } h=1, \\
& <0, \quad \text { for } 0 \leqq h<1 .
\end{aligned}
$$

Hence, (A.9) has solutions only in the range $0<h<\frac{1}{2}$ when $a>0$, and at $h=\frac{1}{2}$ when $a=0$.

Second, we want to show that $\mathrm{d} h / \mathrm{d} a<0$ is consistent with $0 \leqq h \leqq \frac{1}{2}$. Differentiating (A.9), 


$$
\frac{\mathrm{d} h}{\mathrm{~d} a}=\begin{gathered}
-2 a g(h) \\
9 f^{\prime}(h)+a^{2} g^{\prime}(h)
\end{gathered}
$$

where $f^{\prime}(h)$ and $g^{\prime}(h)$ represent partial derivatives of $f(h)$ and $g(h)$ with respect to $h$. Since $g(h)<0, \mathrm{~d} h / \mathrm{d} a<0$ only if the denominator of (A.10) is negative, which corresponds to the second-order condition for profit maximization in location. Hence, $\mathrm{d} h / \mathrm{d} a<0$ if and only if $h$ satisfying (A.9) is a maximum. The functions $f^{\prime}(h)$ and $g^{\prime}(h)$ are not easy to manipulate, but it can be established that $f^{\prime}(h)<0$ for $0.27 \leqq h \leqq \frac{1}{2}$ and $g^{\prime}(h)>0$ for $0 \leqq h \leqq \frac{1}{2}$. The second-order condition can therefore be satisfied only in a subset of this range, found to be $0.33 \leqq h \leqq \frac{1}{2}$. In this range, $\mathrm{d} h / \mathrm{d} a<0$, implying that the entrant maximizes profit by moving closer to the forcign firm as a rises, since, by assumption, the foreign firm's location is $x_{1}=0$.

\section{A.4. Trade and import replacement strategy}

Consider $R_{e}(h=0 ; L, D, t)=R_{e}(h ; L, D, t)$. Using (32) and $a=t / L^{2}$, this equality leads to the polynominal

$$
a^{2}\left[\begin{array}{cc}
2 k_{e}^{2}(h) \\
9 h(1-h)
\end{array}-\begin{array}{c}
k_{e}^{\prime \prime}(h=0) \\
3
\end{array}\right]-a z_{e}^{\prime \prime}(h=0)+\frac{2 z_{e}^{2}(h)}{h(1-h)}=0 .
$$

(A.11) has two positive roots in $a$; one is not feasible since it implies $a>0.823$. The only feasible root, called $a_{I}$, is calculated for various $h$ belonging to the range $0.33 \leqq h \leqq 0.5$ (see section A.3), which gives $0.395 \leqq$ $a_{l} \leqq 0.422$. It can then be verified that $R_{e}(h ; L, D, t)>R_{e}(h=0 ; L, D, t)$ for $a<a_{l}$, so that $h^{*} \neq 0$ is optimal and $R_{e}(h ; t, D, t)<R_{e}(h=0 ; L, D, t)$ for $a>a_{I}$ so that $h^{*}=0$ is optimal.

Since $a \leqq 0.823$ in the trade strategy and $a_{I}$ is always below this limit value, there always exists a well-defined profit-maximizing entrant's location.

Finally, $a_{I}<\tilde{a}_{-1}(h)$, so that the entrant adopts $h^{*}-0$ from values of the parameters which would always allow firm $(-1)$ to have a positive share of market 1 in the trade strategy. Hence, it is optimal for the entrant to replace imports.

\section{References}

d'Aspremont, Claude, Jean Jaskold Gabszewicz and Jacques-François Thisse, 1979, On Hotelling's stability in competition, Econometrica 47, 1145-1150.

Brander, James and Paul Krugman, 1983, A reciprocal dumping model of international trade, Journal of International Economics 15, 313-322.

Caves, Richard, 1982, Multinational enterprise and economic analysis (Cambridge University Press, Cambridge).

Chiang. Alpha, 1984, Fundamental methods of mathematical economics (McGraw-Hill, Tokyo). 
Dixit, Avinash and Victor Norman, 1980, Theory of international trade (James Nisbet and Co., Welwyn).

Eaton, B. Curtis and Richard Lipsey, 1980, Exit barriers are entry barriers: The durability of capital as a barrier to entry, Bell Journal of Economics 16, 282-297.

Eaton, B. Curtis and Myrna Wooders, 1985, Sophisticated entry in an model of spatial competition. The Rand Journal of Economics 16, 282-297.

Gabszewicz, Jean Jaskold and Jacques-François Thisse, 1989, Location, CORE Discussion Paper 8928

Giovannini, Alberto, 1988, Exchange rates and traded goods prices. Journal of International Economics 24, 45-68.

Helpman, Elhanan, 1981, International trade in the presence of product differentiation, economies of scale and monopolistic competition, Journal of International Economics 11, $305-340$

Helpman, Elhanan and Paul Krugman, 1985, Market structure and foreign trade (MIT Press, Cambridge, MA).

I Iorstmann, Ignatius and James Markusen, 1987. Strategic investments and the developments of multinationals, International Economic Review 28, no. 1, 109-121.

Krugman, Paul, 1979, Increasing returns, monopolistic competition and international trade, Journal of International Economics 9, 469-479.

Krugman, Paul, 1980, Scale economies, product differentiation and the pattern of trade, American Economic Review 70, no. 3, 950-959.

Lancaster, Kelvin, 1980, Intra-industry trade under perfect monopolistic competition, Journal of International Economics 10. 151-175.

Lancaster, Kelvin, 1984, Protection and product differentiation, in: Henryk Kierzkowski, ed., Monopolistic competition and international trade (Clarendon Press, Oxford) 137-156.

Lyons, Bruce, 1984, The pattern of international trade in differentiated products, in: Henryk Kierzkowski, ed., Monopolistic compctition and international trade (Clarendon Press, Oxford) $157-179$.

Markusen, James and Tony Venables, 1988, Trade policy with increasing returns and imperfect competition: Contradictory results from competing assumptions, Journal of International Economics 24, $299-316$.

Salop, Steven, 1979, Monopolistic competition with outside goods, Bell Journal of Economics $10,141-156$.

Schmitt, Nicolas, 1990, Two-country trade liberalization in an address model of product differentiation, Canada Journal of Economics 3, no. 23, 654-675.

Tirole, Jean, 1988, The theory of industrial organization (MIT Press, Cambridge, MA). 